\title{
Design and development of a mini scale hot box for thermal efficiency evaluation of an insulation building block prototype used in Bahrain
}

\author{
Payal Modi ${ }^{1}$, Ranya Bushehri ${ }^{1}$, Christina Georgantopoulou ${ }^{1}$, Lazaros \\ Mavromatidis $^{2}$
}

1 School of Engineering, Bahrain Polytechnic, PO Box 33349, Isa Town, Kingdom of Bahrain payal.modi@polytechnic.bh, ranya-bushehri@hotmail.com, christina@polytechnic.bh,

2 ICube UMR7357, Université de Strasbourg,INSA de Strasbourg, 24 Boulevard de la Victoire,67084 Strasbourg Cedex,France, lazaros.mavromatidis@insa-strasbourg.fr

\footnotetext{
*Corresponding author Christina Georgantopoulou, tel: +973 1789 7000, Fax: +973 1789 7049, Christina@polytechnic.bh
}

\begin{abstract}
Building energy consumption is increasing rapidly demanding urgent improvement of insulation techniques in order to promote the buildings energy efficiency. Kingdom of Bahrain presents huge energy demands to the residential buildings due to the continuing air condition units operation. Due to this reason, in the present paper we present the design and development of a modified mini scale hot box experimental apparatus as well as an experimental and an analytical investigation of the used insulation blocks and techniques in Bahrain, with the aim to measure and evaluate the thermal resistance. The experimental process is developed on the basis of a standardized hot - box design and manufactured with appropriate dimensions, in order to measure the temperature distribution according various climate conditions. Important results and estimations are produced concerning the thermal resistance of insulation blocks, temperature distribution and heat transfer coefficients. The results are accurate enough and these are validated with the corresponded ones of the literature, of analytical calculations as well as of the manufacture side. It seems that the insulation blocks efficiency is adapted to the regional climate conditions and possible reliable solutions can be applied for further improvement.
\end{abstract}

Key Words:

Thermal resistance, R-value, thermal insulation, insulation blocks, guarded hot box, U-value. 


\section{Introduction and General Context}

Building energy efficiency is one of the most important research issues in the modern time, and various techniques have been developed in order to improve it. Especially in the Middle East Region where the demand of air-conditioning is too high, a great need for efficient buildings design has been created. In the Kingdom of Bahrain more than $60 \%$ of the energy is consumed by air conditioning, fact which demands the buildings insulation techniques to be in high performance [1].

The numerical simulation of the building walls as well as the computational estimation of the heat transfer ratio is critical in order to identify possible ways of efficiency improvement. Zhou [2] has presented a finite element analysis for a three store building simulation trying to identify and improve the insulation material resistance, while Mavromatidis [3] has an interesting one dimensional approach for multilayer insulation trying to propose the optimum configuration according to the geographical location [4], or the appropriate accurate numerical methodology in order to reduce the error during the computational technique [5] .An interesting model for thermal processes in buildings has been developed by Zupancic [6,7] where object-oriented approach is applied. The interest is focused on the performance and effectiveness of insulation materials like polystyrene or various structures $[8,9]$ or on the building energy optimization in specific locations according to the climate [10,11, and 12].

Most of the times the experimental investigation is highly important which in combination with numerical modeling applications is able to provide accurate results and proposals for more effective insulation techniques [13], while various experimental methods, design and approaches have been presented in order to investigate the possible enhancement of building efficiency according to multiple variables and conditions $[14,15]$ or to identify the optimal thermal insulation strategy [16]. Building materials investigation concerning the thermal efficiency or the moisture properties has been extensively recently developed as in Becker's [17] or Saber's work [18]. Additionally concrete properties, thermal 
resistance or optimization of its behavior concerning with the environment has been explored using, developing, testing and applying numerous experimental techniques [19, 20].

\subsection{Aims and scope}

In the present paper we try to experimentally investigate the efficiency of the used blocks in residential buildings in Bahrain. The building energy effectiveness is high important in this region due to the high temperature for more than half of the year [21]. Statistics data have been collected in order to identify the ways of insulations in buildings in Bahrain as well as the most popular blocks - bricks. A few approaches have been already developed in similar aspects as the ones of Hadhrami and Nuaimi $[22,23]$ with interesting results regarding the $\mathrm{U}$ and $\mathrm{R}$ value estimation according to the outdoor temperature conditions. In order to manage to measure the blocks thermal properties we designed and constructed a hot - cold box in order to simulate the environment conditions making the least possible assumptions. The above approach is used in various other test cases with satisfied results and it promises an effective way in order to test the insulation blocks thermal efficiency $[24,25,26,27]$. Out results are compared with the corresponded analytical as well as manufacturers' ones with accepted accuracy. Multiple measurements have been achieved trying to achieve steady state and minimize the outdoor impact simultaneously while specific interest has been given to the box design and manufacture in order to ensure as much as it is possible the accuracy of the measurements.

\section{Theory and calculations}

\subsection{Thermal Efficiency and insulation}

Thermal insulation is a term used to describe a material/product that has the purpose of limiting heat transfer between a barrier/wall. The usage of thermal insulation is important to reduce the use of electricity hence reducing monthly electrical bill of home or flat users and maintain a comfortable indoor 
environment according to the outdoor temperatures. However, according to the geographical location of each building, the heating or the cooling used system performance is maximized reducing the energy consumption.

\subsection{Thermal resistance and $U$ value}

The thermal resistance of each material which is used for buildings' construction purposes is related to the temperatures distribution around the walls and the roof. If we assume a block of an external building's wall (fig. 1), a combination of conduction, convection and radiation is developed in order the heat to be transferred through the block (left side of the block), while heat rate exchange by convection is happening to the other side (right side of the block - indoor surface). If we neglect the radiation heat effect, it applies as:

$$
Q_{h \mathrm{Conv}}=Q_{\text {Cond }}=Q_{\text {c Concv }}
$$

where $\mathrm{Q}_{\mathrm{h} \text { Conv }}\left(\mathrm{W} / \mathrm{m}^{2}\right)$ is the heat convection rate from the heat source to the "hot" wall, $\mathrm{Q}_{\text {Cond }}\left(W / \mathrm{m}^{2}\right)$ the heat conduction rate through the block and $\mathrm{Q}_{\mathrm{c} \text { Concv }}\left(W / \mathrm{m}^{2}\right)$ the heat convection rate again but now from the block to

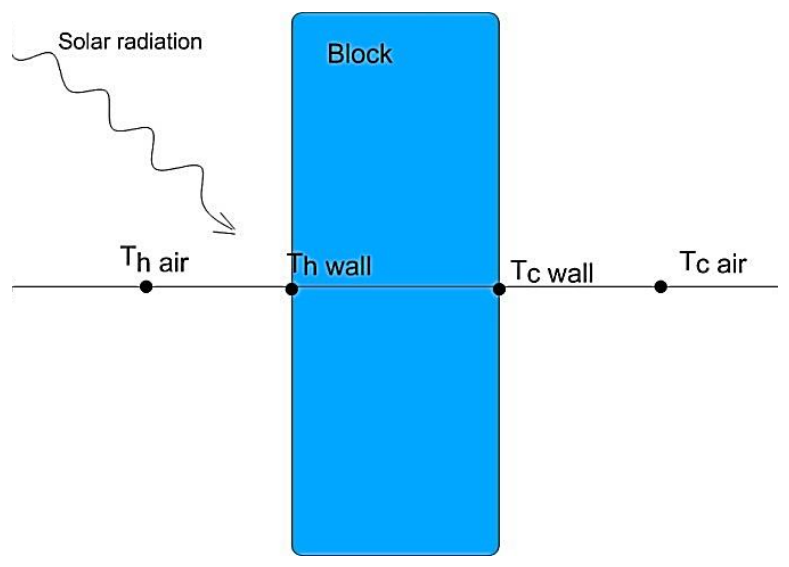

Figure 1: Thermal resistance network

the "cold" air. If we define and name the various temperatures values in different points of the system as it can be seen at figure 1 then the equation 2 can be reformed as: 


$$
\frac{T_{h \text { air }}-T_{h \text { wall }}}{R_{\text {Hot air }}}=\frac{T_{h \text { wall }}-T_{c \text { wall }}}{R_{\text {Block }}}=\frac{T_{c \text { wall }}-T_{c \text { air }}}{R_{\text {Cold air }}}
$$

where $T_{h \text { wall }}\left({ }^{\circ} \mathrm{C}\right)$ is the surface temperature of the block facing the heat source, $T_{c \text { wall }}\left({ }^{\circ} \mathrm{C}\right)$ the surface temperature of the block facing the gypsum sheet, $T_{c \text { air }}\left({ }^{\circ} \mathrm{C}\right)$ the temperature of the cold air while $R_{\text {Hot air }}\left(\mathrm{m}^{2}{ }^{0} \mathrm{C} / \mathrm{W}\right)$, $R_{\text {Block }}\left(\mathrm{m}^{2}{ }^{0} \mathrm{C} / \mathrm{W}\right)$ and $R_{\text {Cold air }}\left(\mathrm{m}^{2^{0}} \mathrm{C} / \mathrm{W}\right)$ are the thermal resistances of the hot air, block and cold air respectively. The thermal resistances are defined as below:

$$
R_{\text {hot air }}=\frac{1}{h_{h}} R_{\text {cold air }}=\frac{1}{h_{c}} R_{\text {block }}=\frac{l}{k}
$$

where $h_{h}\left(W / m^{2} K\right)$ and $h_{c}\left(W / m^{2} K\right)$ the convective heat transfer coefficient for air, while $k(W / m K)$ the conductive coefficient of the block and $l(m)$ the width of the block (fig. 1). To all the above definition we assume that the R unit $\left(m^{2}{ }^{0} \mathrm{C} / W\right)$ is equally expressed with $\left(m^{2} K / W\right)$.

Although $\mathrm{R}$ - values are used in order to define and present the behavior and performance of insulation material the thermal transmittance, $\mathrm{U}\left(W / \mathrm{m}^{2}{ }^{0} \mathrm{C}\right)$, is calculated in order to identify the insulation thermal behavior of a building component. The $\mathrm{U}$ - value is defined as below:

$$
U=\frac{1}{R_{\text {hot air }}+R_{\text {block }}+R_{\text {cold air }}}
$$

where the symbols are as these are defined above [24].

\subsection{Convection coefficient of air}

As it has been presented to at the above part, in order to calculate the $\mathrm{R}$ of the block, the $\mathrm{Q}$ amount calculation is demanded. For this reason the properties of the air in average temperature need to be identified. These properties are the thermal conductivity, density, kinematic viscosity, specific heat, coefficient of thermal expansion and the dynamic viscosity. When considering that the convection is in a confined space it is noted that the surface temperatures needs to be considered [4], as these are depicted at figure 1. The convection heat transfer coefficient of air can be calculated as is shown below: 


$$
h=\frac{N u \times k}{x}
$$

where $N u$ (dimensionless) is the Nusselt number, $k(W / m K)$ the thermal conductivity of air and $x(m)$ the thickness of the air gap. Nusselt number is calculated as follow although more formulas can be obtained:

$$
N u=\left\{1+\left[\frac{0.104 \times R a^{0.293}}{1+\left(\frac{6310}{R a}\right)^{1.36}}\right]^{3}\right\}^{1 / 3}
$$

where $R a($ dimensionless) is the Reyleigh number which is defined as:

$$
R a=G r \times P r
$$

where Gr(dimensionless) is the Grashof and $\operatorname{Pr}$ (dimensionless) the Pradtl number whose the formulas are:

$$
G r=\frac{g \beta(T 1-T 2) x^{3}}{v^{2}}
$$

and

$$
\operatorname{Pr}=\frac{\mu \times C p}{k}
$$

where $g\left(\mathrm{~m} / \mathrm{s}^{2}\right)$ is Gravitational acceleration, $x(\mathrm{~m})$ the thickness of the air gap, $\beta\left(K^{-1}\right)$ the coefficient of volume expansion, $v\left(\mathrm{~m}^{\mathrm{s}} / \mathrm{s}\right)$ the kinematic viscosity while $T 1\left({ }^{\circ} \mathrm{C}\right), T 2\left({ }^{\circ} \mathrm{C}\right)$ are the surface temperatures at the boundaries of the gap $[3,4]$.

\section{Materials and Methods}

\subsection{Concrete blocks - insulation in Bahrain}

Buildings energy efficiency is highly demanding in Middle East countries as in Bahrain, where the annual average temperatures are between $30^{\circ} \mathrm{C}$ to $32^{\circ} \mathrm{C}$ and the air-conditioning usage is necessary for most of the months of the year (fig. 2,3). However during winter, the temperature may drop to $10^{\circ} \mathrm{C}$ but with the additional wind factor the temperature may feel as low as $3^{\circ} \mathrm{C}[28]$. Due to Bahrain's extreme climate 
conditions the use of thermal insulation material in external wall in buildings may help out during both seasons, prevent heat transfer during summer from outdoors to indoors and prevent also the heat escaping from indoors to outdoors during winter (table 1).

Electricity and Water Authorities (E.W.A.) in Bahrain have developed an extended analysis concerning the appropriate limits for the insulation in buildings in the country providing important information for insulation techniques and blocks [29]. According to their insulation limits, they propose techniques, make these available to the related engineers and constructors. It seems that the usage of concrete blocks, the external thermal insulation composite system as well as the internal insulation for walls are the main proposed techniques accomplishing the appropriate criteria for the country (table 2). However as it will be presented below, the concrete blocks applications seems to be the most popular insulation technique in Bahrain in domestic houses and multi - story buildings.

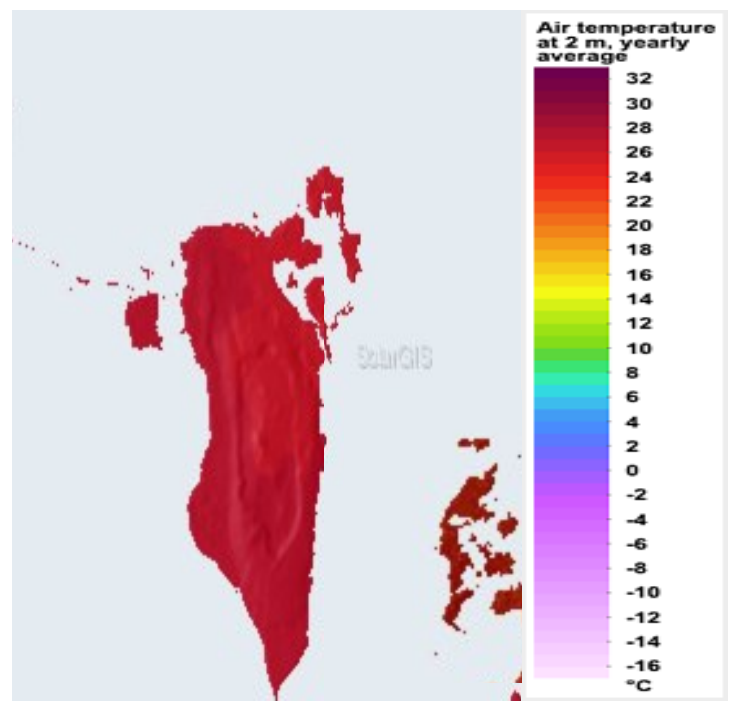

Fig. 2: Average annual Temperature in Bahrain [21]

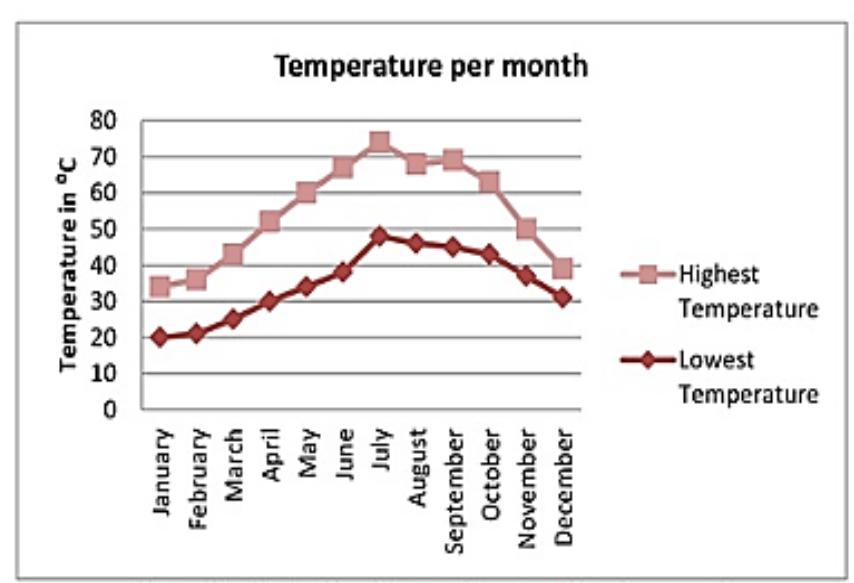

Fig. 3: Highest and lowest temperatures per month, in Bahrain [23]. 
Table 1: Insulation Techniques

\begin{tabular}{|l|l|}
\hline External Thermal Insulation Composite System & Internal insulation walls \\
\hline Concrete blocks with insulation and sandwich blocks \\
\hline
\end{tabular}

Table 2 - Domestic building blocks

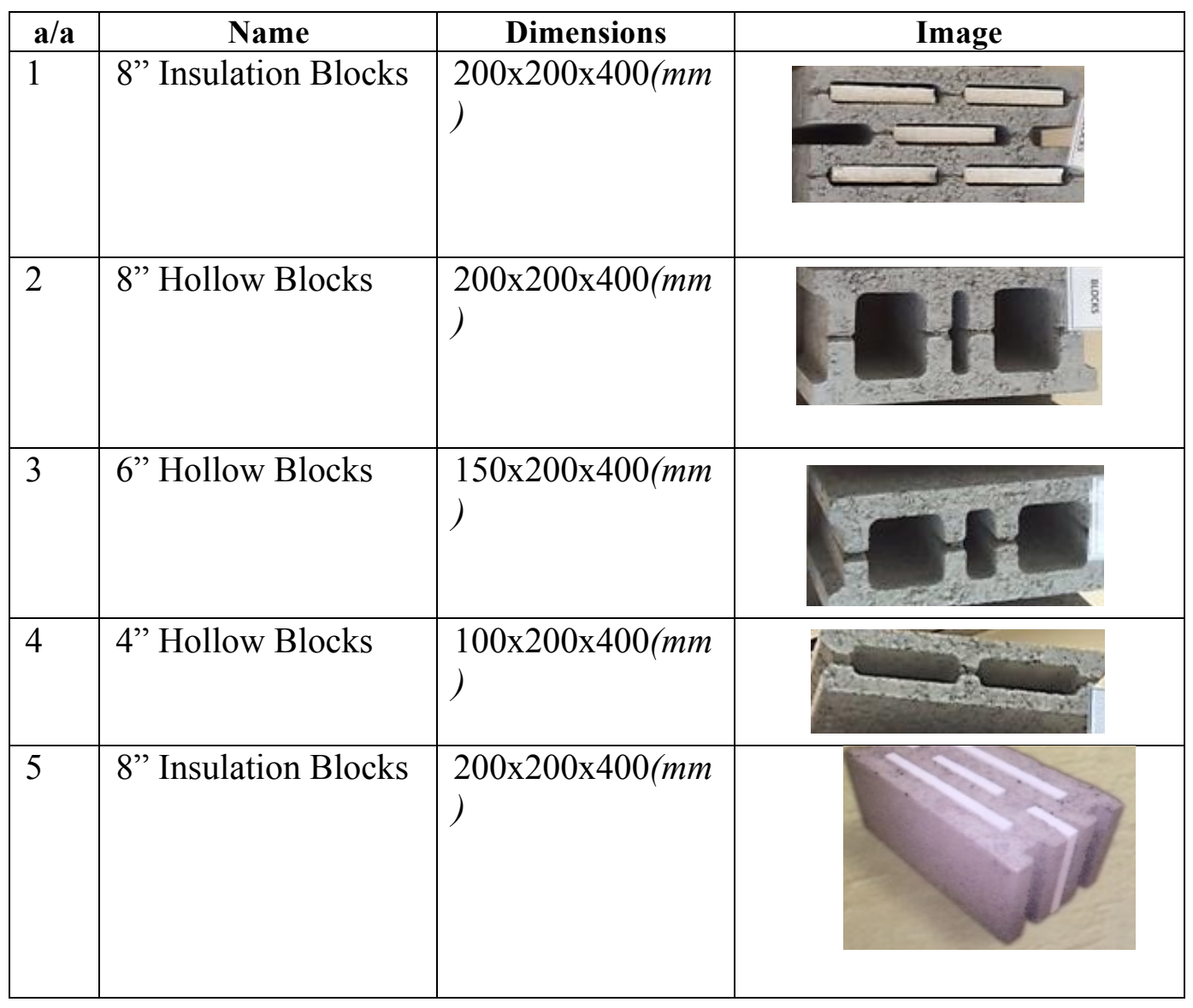




\begin{tabular}{|c|c|c|c|}
\hline 6 & 8" Sandwich block & $200 \times 200 \times 400(\mathrm{~mm}$ & \\
\hline 7 & 12" Sandwich block & $300 \times 200 \times 400(\mathrm{~mm}$ & \\
\hline 8 & $\begin{array}{l}\text { 8" Leca Slotted } \\
\text { Block }\end{array}$ & 200x $200 \times 400(\mathrm{~mm}$ & \\
\hline 9 & 8'' Clay Block & 200x200x400( $\mathrm{mm}$ & 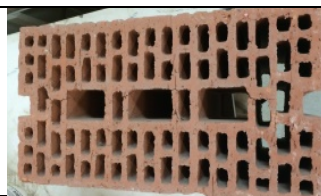 \\
\hline
\end{tabular}

According to E.W.A. the thermal insulation department stipulates that the overall heat transfer coefficient (U-value) should not exceed $0.75 \mathrm{~W} / \mathrm{m}^{2}{ }^{\circ} \mathrm{C}$ hence the R-value should be higher than $1.33 \mathrm{~m}^{2}{ }^{\circ} \mathrm{C} / \mathrm{W}$ for the external walls. For roofs however the U-value should not exceed $0.6 \mathrm{~W} / \mathrm{m}^{2}{ }^{\circ} \mathrm{C}$ (higher then R-value $\left.1.67 \mathrm{~m}^{2}{ }^{\circ} \mathrm{C} / \mathrm{W}\right)$. However, as the most popular insulation techniques in Bahrain is the use of concrete blocks, more designs with various thermal properties are used according to the size and location of each building (table 2). According to the company any method can be applied if it meets the above E.W.A. requirements.

All the blocks mentioned are high density blocks made with RAK aggregate. It seems that tone of the most popular concrete blocks to the domestic buildings construction is the 8 " insulated slotted blocks due to the low cost with adequate insulation performance simultaneously (U-value of $0.63 \mathrm{~W} / \mathrm{m}^{2}{ }^{\circ} \mathrm{C}$ and $\mathrm{R}$ value $1.58 \mathrm{~m}^{2}{ }^{\circ} \mathrm{C} / \mathrm{W}$ according to the manufacturer). 
The blocks are usually manufactured with RAK aggregate but if requested this can be replaced by Leca making the block have lower density (1/3 of RAK aggregate blocks). However it seems that the block then will present lower compressive strength. In the past sandwich blocks used to be manufactured which are characterized by high Rvalues but very high rejection percentage too. Additionally it is possible that clay blocks (table 2) are very efficient with high heat resistance property but this will be an issue for further research.

The concrete of the blocks can be changed depending on customers'request which includes RAK or leca aggregate and many other alternative materials. Although Leca is a high quality material, it seems that its compressive strength is lower than E.W.A. standards. By the other hand sandwich blocks are effective enough concerning their thermal resistance but they cannot bear load appropriate enough for every construction demand. For all the above reasons in combination of the normal cost demand per unit, 8 " slotted blocks also known as insulation blocks, are highly applied and used in domestic buildings construction and preferred either by the construction companies, either by the houses owners.

\subsection{Experimental hot box unit design and tested materials}

The main purpose of our work is the experimental investigation of the thermal resistance and $U$ factor of insulation blocks and the possible internal or external insulation techniques. In order to succeed it a modified mini scale "hot box" has been decided to be manufactured trying to simulate the outdoor and indoor conditions of a part of a domestic building's wall.

\subsection{Design of Experimental Set-up of experimental apparatus}

The dimensions, the shape as well as the material of the experimental unit $($ fig. 4,5$)$ have been decided according to the main purpose of the experiments; to study and measure the thermal efficiency of the insulation concrete blocks. However similar designs have developed by other researchers which present various differences mainly to the structure according to the case $[23,25,31,32$, and 33$]$.

The following is the list of components that will be used to make the experimental set up and the components that will be placed inside (table 3). These dimensions determine the final design. 


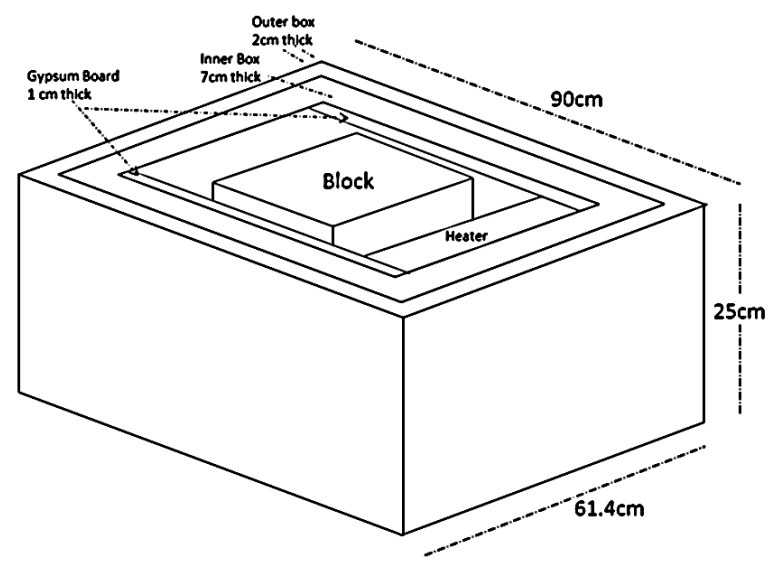

Figure 4: Arrangement and final dimensions of the experimental box

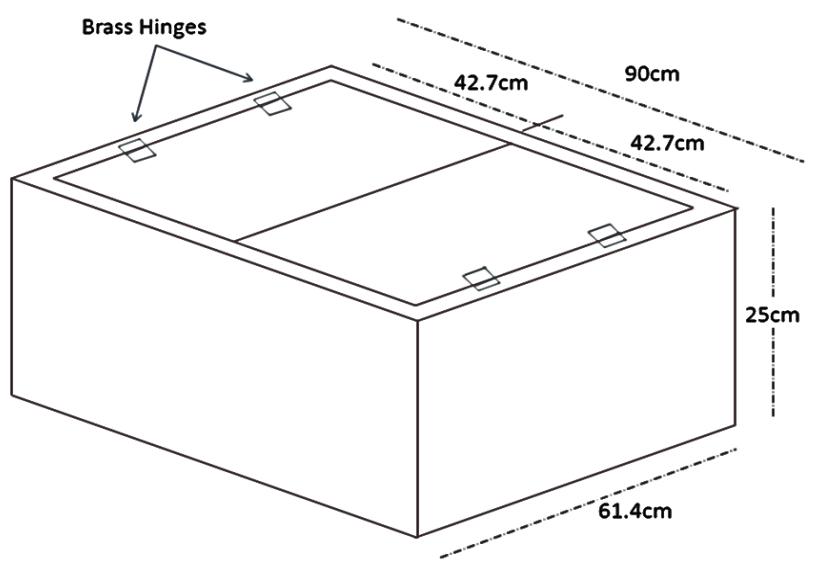

Figure 5: Top view initial design of the "box"

Table 3: Experimental unit main components

\begin{tabular}{|c|c|}
\hline Main components & Type or Dimensions (mm) \\
\hline Heat Source & $200 \times 15 \times 105$ \\
\hline Copper sheet & $400 \times 1 \times 200$ \\
\hline MDF board & $\begin{array}{l}\text { Thickness: } 19 \mathrm{~mm} \\
\text { (fig.5) }\end{array}$ \\
\hline Box insulation material & Thickness: $12.5 \mathrm{~mm}$ (fig.5) \\
\hline $\begin{array}{ll}\text { Sample: } & \text { Concrete } \\
\text { Block } & \end{array}$ & $400 \times 200 \times 200$ \\
\hline Temperature sensors & $\mathrm{T}$ - type (5 pieces) \\
\hline
\end{tabular}

Initial rough sketches have been designed of the experimental set up with the given dimensions of the items and the MDF board. However at a second stage, CAD designs have been developed providing the appropriate details concerning the final dimensions, materials and the parts joining techniques.

In this case the minimization of the heat transfer losses through the boxes walls and the reduction of thermal bridges were fundamental as these affect the precedence of our results accuracy and the value of the relevant error. At the following figures (fig. 6,7) various hot - box designs are presented, providing specific details concerning the final construction, while at the figure 8 , the final internal box view is depicted, as the sample has been placed inside. At figure 9, it is presented the manufacturing process which has been followed in order to construct the experimental unit. 


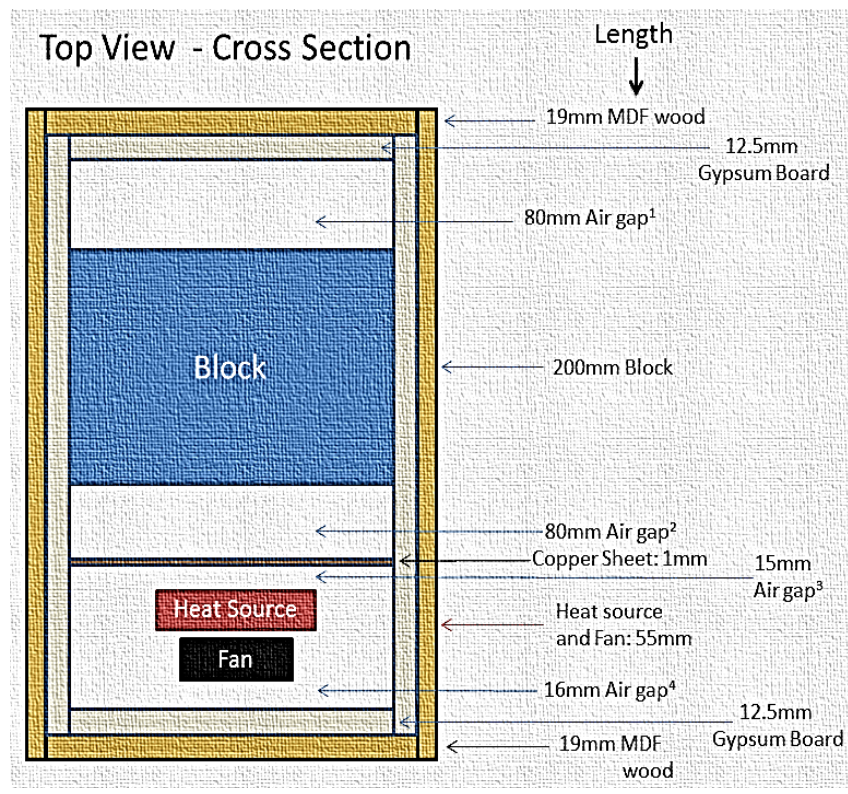

Figure 6: Rough sketch of the experimental set up (Top view - Cross section)

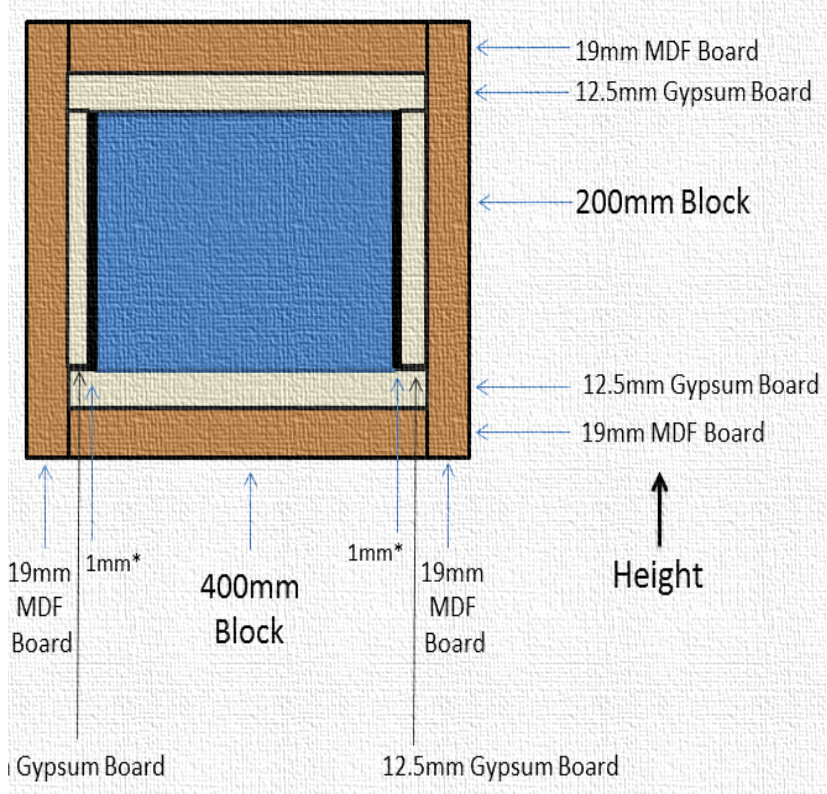

Figure 7: Rough sketch of experimental set up. (Front view - Cross section)

The following table 4 is a bill of material table showing the dimensions of the parts needed to make the experimental set up and the inner surface insulation gypsum board.

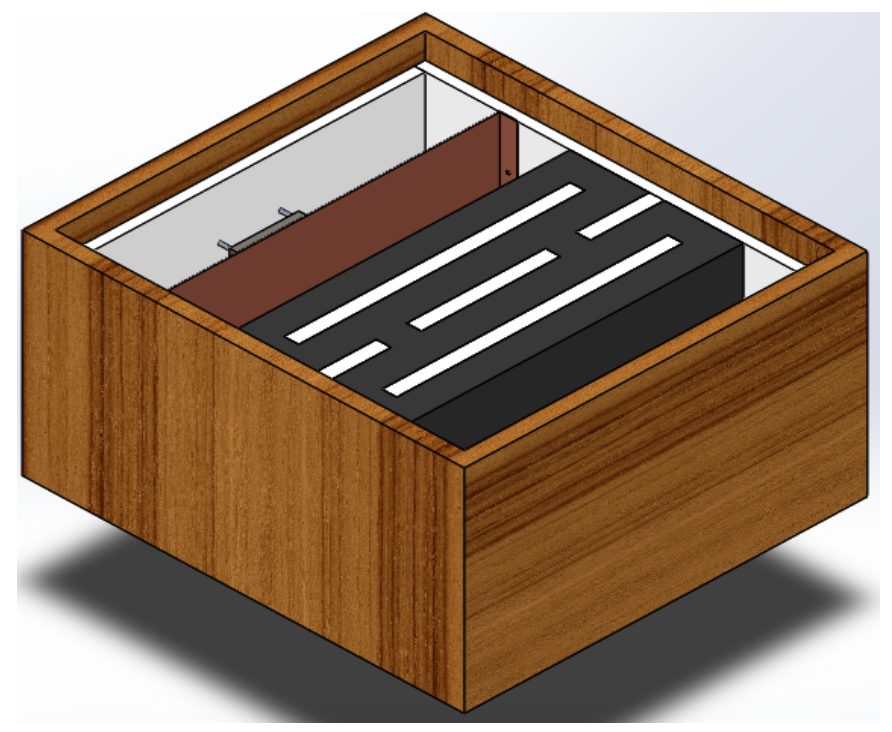

Figure 8: Hot box with the sample: 3-D SolidWorks Model

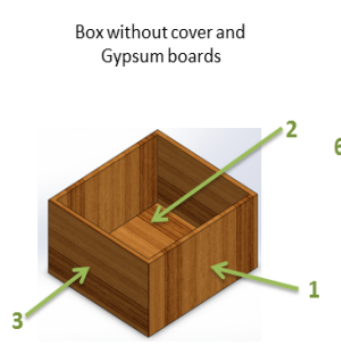

Boxwithout cover but with bottom, side and front Gypsum boards

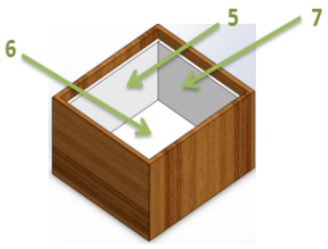

Box without cover but with all Gypsum boards

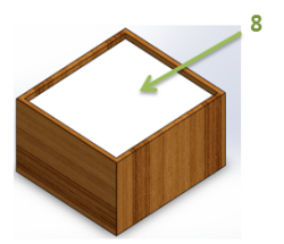

Completed Box

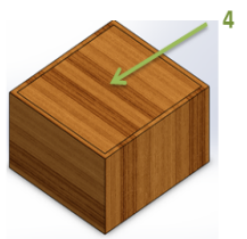

Figure 9: Hot box designs: 3-D images at different stages 
Table 4: Bill of material

\begin{tabular}{|c|c|c|c|}
\hline $\mathbf{a} / \mathbf{a}$ & Label & Qtty & Dimensions (Tolerance) \\
\hline 1 & $\begin{array}{l}\text { Side Plane Board } \\
\text { MDF }\end{array}$ & 2 & $\begin{array}{l}510 \mathrm{~mm}(+/-2 \mathrm{~mm}) \times 263 \mathrm{~mm} \\
(+/-2 \mathrm{~mm}) \times 19 \mathrm{~mm} \\
2 \mathrm{~mm})\end{array}$ \\
\hline 2 & $\begin{array}{l}\text { Bottom Plane Board } \\
\text { MDF }\end{array}$ & 1 & $\begin{array}{l}472 \mathrm{~mm}(+/-1 \mathrm{~mm}) \times 427 \mathrm{~mm} \\
(+/-1 \mathrm{~mm}) \times 19 \mathrm{~mm}(+/-2 \mathrm{~mm})\end{array}$ \\
\hline 3 & $\begin{array}{l}\text { Front Plane Board } \\
\text { MDF }\end{array}$ & 2 & $\begin{array}{l}427 \mathrm{~mm}(+/-1 \mathrm{~mm}) \times 263 \mathrm{~mm} \\
(+/-1 \mathrm{~mm}) \times 19 \mathrm{~mm}(+/-2 \mathrm{~mm})\end{array}$ \\
\hline 4 & $\begin{array}{l}\text { Top cover Board } \\
\text { MDF }\end{array}$ & 1 & $\begin{array}{l}472 \mathrm{~mm}(+/-1 \mathrm{~mm}) \times 427 \mathrm{~mm} \\
(+/-1 \mathrm{~mm}) \quad \times \quad 19 \mathrm{~mm} \quad(+/- \\
2 \mathrm{~mm})\end{array}$ \\
\hline 5 & $\begin{array}{l}\text { Side Insulation Boards } \\
\text { Gypsum }\end{array}$ & 2 & $\begin{array}{l}472 \mathrm{~mm}(+/-1 \mathrm{~mm}) \times 200 \mathrm{~mm} \\
(+/-1 \mathrm{~mm}) \times 12.5 \mathrm{~mm} \\
1 \mathrm{~mm})\end{array}$ \\
\hline 6 & $\begin{array}{l}\text { Bottom Insulation } \\
\text { Board } \\
\text { Gypsum }\end{array}$ & 1 & $\begin{array}{l}472 \mathrm{~mm}(+/-1 \mathrm{~mm}) \times 427 \mathrm{~mm} \\
(+/-1 \mathrm{~mm}) \times 12.5 \mathrm{~mm} \\
1 \mathrm{~mm})\end{array}$ \\
\hline 7 & $\begin{array}{l}\text { Front Insulation Boards } \\
\text { Gypsum }\end{array}$ & 2 & $\begin{array}{l}402(+/-1 \mathrm{~mm}) \times 200 \mathrm{~mm} \\
(+/-1 \mathrm{~mm}) \times 12.5(+/-1 \mathrm{~mm})\end{array}$ \\
\hline 8 & $\begin{array}{l}\text { Top Insulation Board } \\
\text { Gypsum }\end{array}$ & 1 & $\begin{array}{l}472 \mathrm{~mm}(+/-1 \mathrm{~mm}) \times 427 \mathrm{~mm} \\
(+/-1 \mathrm{~mm}) \times 12.5 \mathrm{~mm} \\
1 \mathrm{~mm})\end{array}$ \\
\hline
\end{tabular}

The insulation material of the unit has been chosen to be Gypsum as it appears appropriate properties for our case. Its most important characteristics are the rigidity which is very high, its non- flammability as well as its simple and easy application. However, in our future experiments the DEI heat screen material may be chosen due to its higher thermal resistance property.

In order to achieve the high temperature at the hot area of the box as well as to facilitate temperature uniformity along the same area, a fan has been adjusted close to the heat source. Finally electronic components have been fastened onto an acrylic board stand, in order to control the power of the unit (fig. 10). As we have already mentioned, the block, (fig. 11), which will be tested in the experimental set up, is the 8 " insulation (slotted) block since this type of block is frequently manufactured and supplied by most companies in Bahrain. Sample of 8 " insulation block to be used has manufacturing R-value of $1.58 \mathrm{~m}^{2}{ }^{\circ} \mathrm{C} / \mathrm{W}$. 


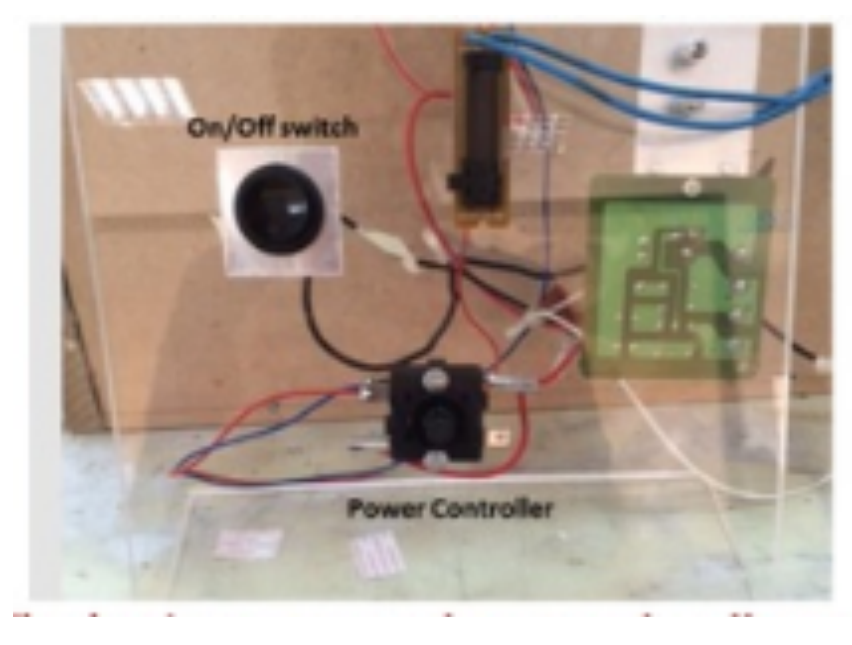

Figure 10: Experimental unit: Electronic components

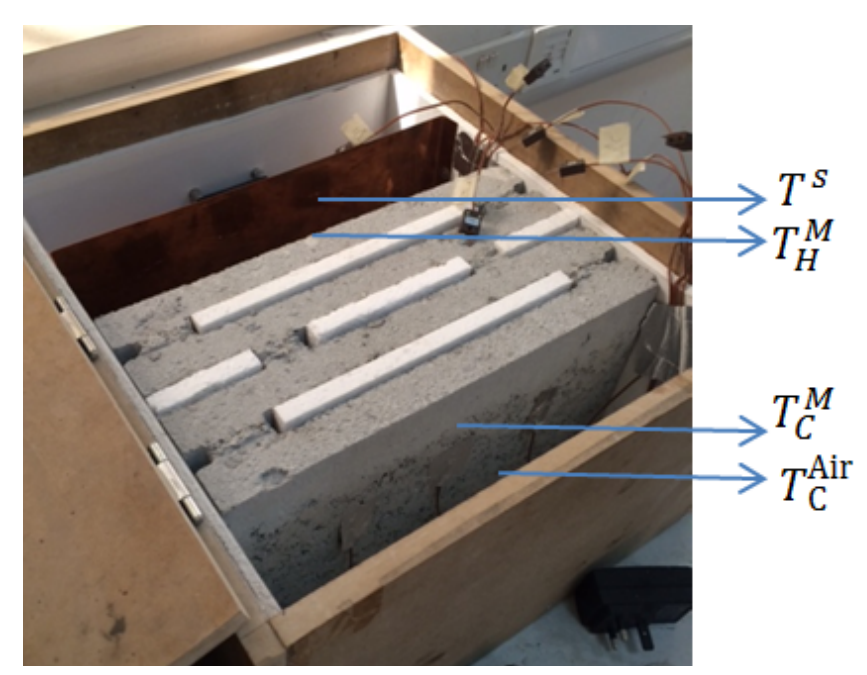

Figure 11: Final manufactured experimental set up

\subsection{Software Based Temperature Control Strategy}

Major importance regarding the accuracy of the final measurements as well as the achievement of steady state plays the temperature control. In order to achieve it, we choose to apply a PID controller method fixing the desired temperature of the hot area of the box to the desired point. As it is known a PID controller is able to calculate the error and the difference among the set point temperature and the measured temperature values according to the time [34]. After the PID evaluation an on-off technique is implemented. Various measurements have been developed in order to test the efficiency of the temperature control strategy. At the following figure 12 the desired final temperature is set equal to $45^{\circ} \mathrm{C}$ while the ambient temperature has been measured as $21.6^{\circ} \mathrm{C}$.

\section{Results and discussion}

The experiments which are taken place have been developed receiving the related measurements under the following assumptions:

- One - dimensional conduction and convection on the $\mathrm{x}$ direction.

- No heat losses take place through the hot-box walls. 


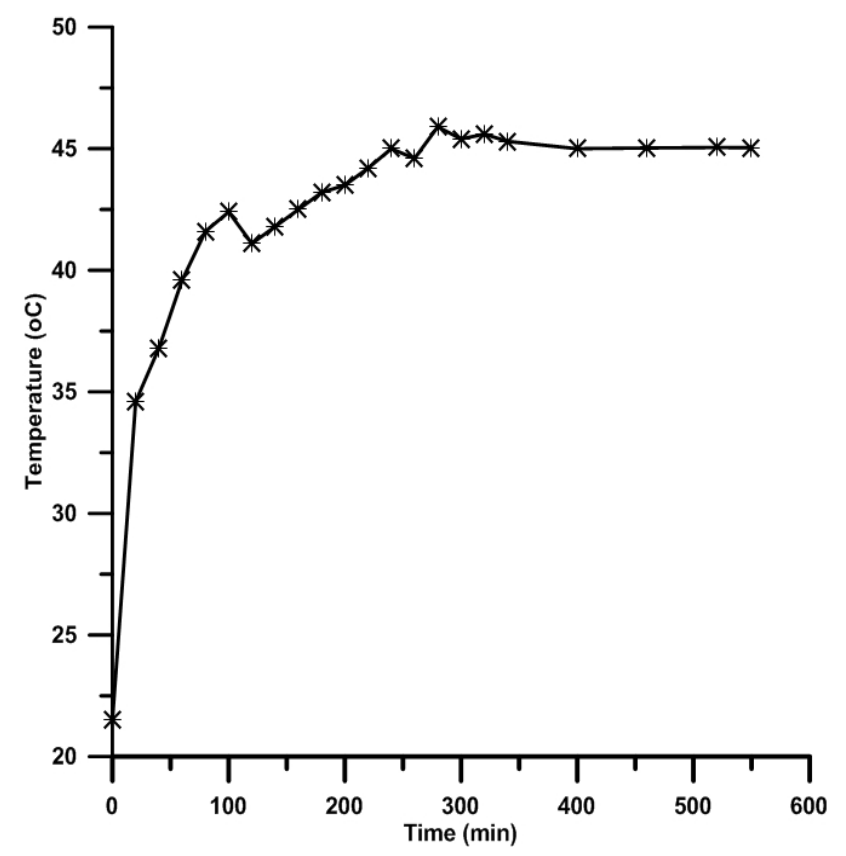

Figure 12: Time temperature graph. Set point $45^{\circ} \mathrm{C}$ and ambient temperature $21.6^{\circ} \mathrm{C}$.

- Steady state has been achieved during the final measurements

- The temperature at the "hot" side of the box is distributed uniformly along the area.

- No air flow occurs between the hot and cold area of the experimental box.

- The radiation effect has been neglected. Only convection and conduction mechanisms have been measured and calculated at this phase.

- The mortar type effects haven't been assumed.

\subsection{Temperature measurements and R-value calculation}

Various test runs have been performed placing the thermocouples as it is depicted at figure 11. The temperature distribution according to the time in order steady state to be achieved is presented at figures 13 and 14 . Through these graphs an appropriate distribution is presented showing a normal behavior of the heat transfer rate. This can be concluded by figure 15 also, where the temperature distribution is presented for three different outdoor temperature values (Tsource). Considering the outdoor temperature equal to $45^{\circ} \mathrm{C}$, the temperature distribution 
along the concrete block from the "hot" to the "cold" side when steady state has been achieved, is presented at figure 16.
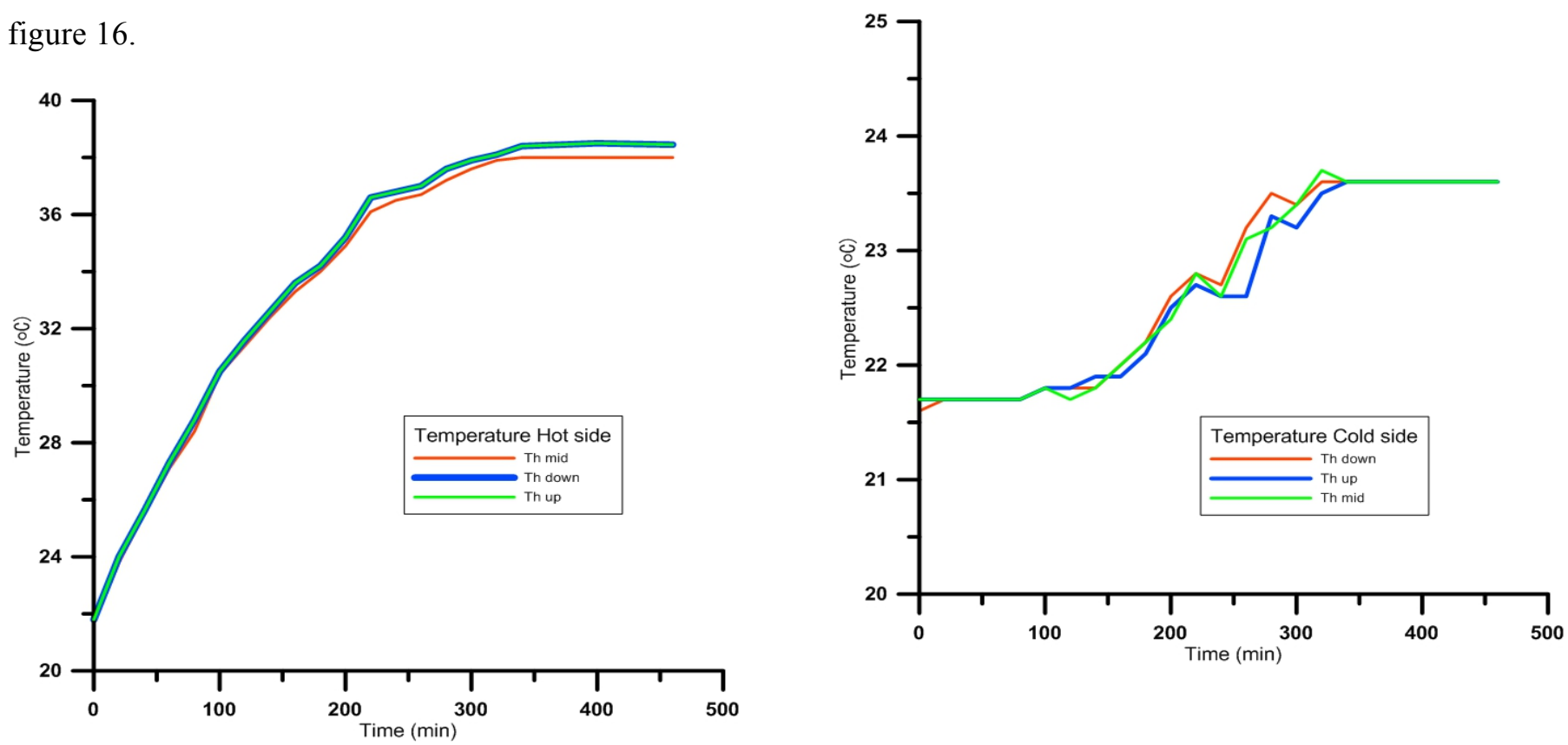

Figure 13,14: Temperature distribution according to the time to the hot side and cold side of the concrete block respectively.

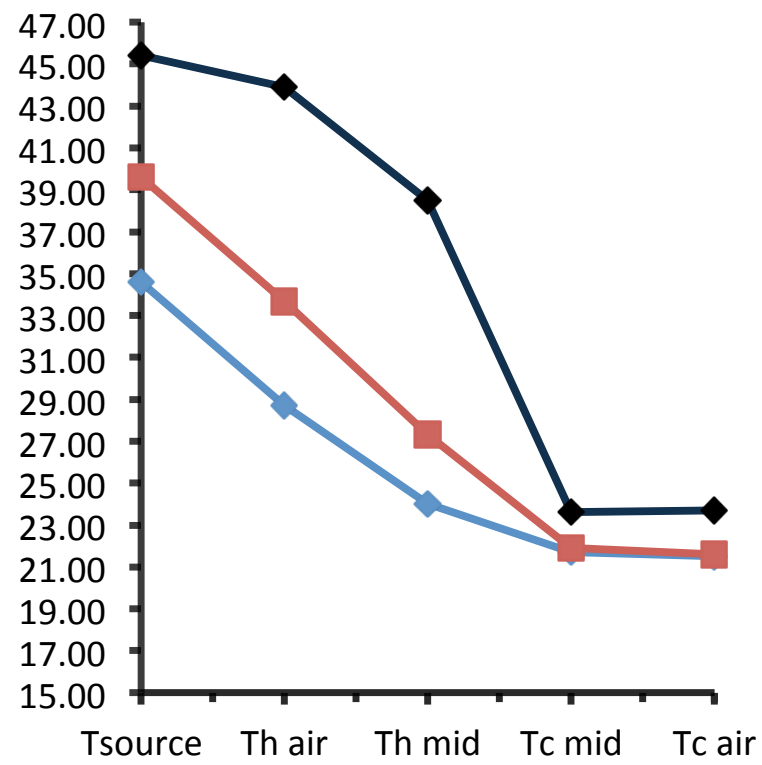

Figure 15: Temperature distribution $\left({ }^{\circ} \mathrm{C}\right)$ along the concrete block for different heat source temperatures. Blue line: Tsource $=35^{\circ} \mathrm{C}$. Red line: Tsource $=40^{\circ} \mathrm{C}$. Black line: Tsource $=45^{\circ} \mathrm{C}$. Steady state. 


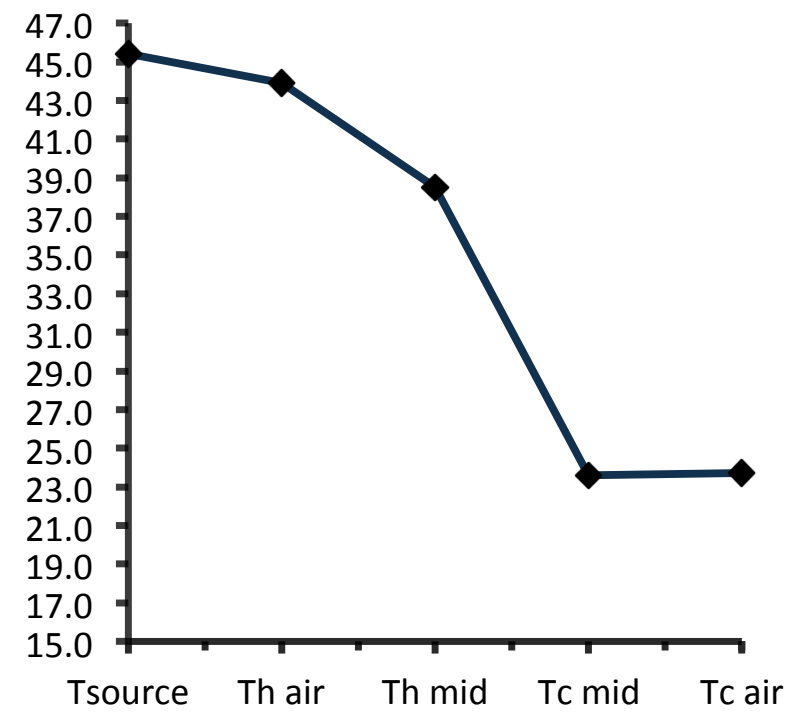

Figure 16: Temperature distribution $\left({ }^{\circ} \mathrm{C}\right)$ at the steady state along the concrete block; from the hot side to the cold one. (Thot air $\left.=45.00^{\circ} \mathrm{C}\right)$

According to the outdoor temperature the air properties can be calculated using the appropriate formulas and tables. The air properties for $\mathrm{T}=45^{\circ} \mathrm{C}$ are presented below:

- Thermal Conductivity, $k=0.026805 \mathrm{~W} / \mathrm{mK}$

- Density, $\rho=1.118 \mathrm{~kg} / \mathrm{m}^{3}$

- Kinematic viscosity, $v=1.726 \times 10^{-5} \mathrm{~m}^{\mathrm{s}} / \mathrm{s}$

- Specific heat, $C p=1007 \mathrm{~J} / \mathrm{kgK}$

- Coefficient of thermal expansion, $\beta=0.0031695721 K^{-1}$

- Dynamic viscosity, $\mu=1.726 \times 10^{-5} \times 1.118=1.929668 \times 10^{-5} \mathrm{~kg} / \mathrm{m}$

Applying the equations (2) to (9) as well as the experimental measurements we can extract the thermal resistance value as it is presented analytically in the table 5 .

For validation purposes, we will not only use the experimental values from the manufacturer but also the analytical results, if we apply the heat transfer equations and formulas. Facing the concrete block as a multi - layer composed material (fig. 17) and knowing the appropriate dimensions, the analytical calculation of the thermal resistance is simple. It is based on the partial sub thermal resistances of each material and each layer. 
Table 5: Experimental analysis values $-\mathrm{R}$ value

\begin{tabular}{|c|}
\hline $\operatorname{Pr}=0.72$ \\
\hline$G r=3.3 \times 10^{5}$ \\
\hline$R a=2.4 \times 10^{5}$ \\
\hline$N u=3.95$ \\
\hline$h=1.29 \mathrm{~W} / \mathrm{m}^{2} \mathrm{~K}$ \\
\hline$R_{\text {conv }}=0.7743 \mathrm{~m}^{2^{0}} \mathrm{C} / \mathrm{W}$ \\
\hline$Q=8.91 \mathrm{~W} / \mathrm{m}^{2}$ \\
\hline $\boldsymbol{R}_{\text {Block }}=\mathbf{1 . 6 7} \mathbf{m}^{\mathbf{2}} \boldsymbol{C} / \boldsymbol{W}$ \\
\hline
\end{tabular}

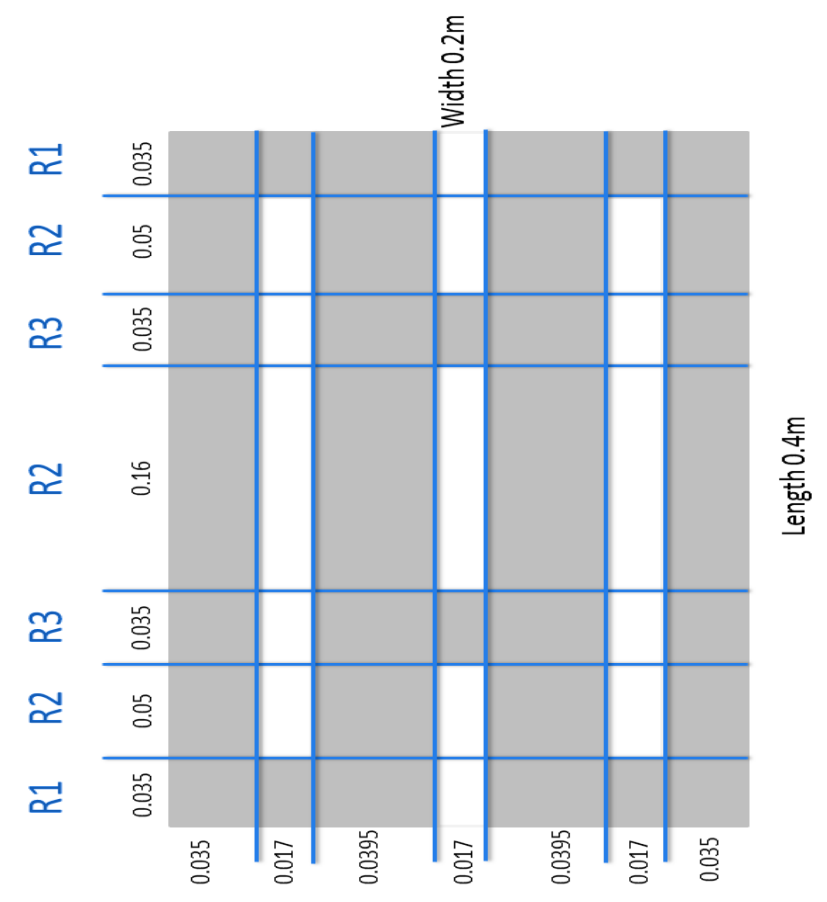

Figure 17: Top view structure, schematic and dimensions for the 8 " block If we assume the below values from the manufacturer:

- Thermal conductivity ( $\mathrm{k}$-value) of concrete $=1.3 \mathrm{~W} / \mathrm{mK}$ and

- Thermal conductivity ( $\mathrm{k}$-value) of polystyrene $=0.037 \mathrm{~W} / \mathrm{mK}$, the following results are produced:

$$
\begin{aligned}
& R 1=0.6000 \mathrm{~m}^{2^{0}} \mathrm{C} / W \\
& R 2=1.4900 \mathrm{~m}^{2^{0}} \mathrm{C} / W \\
& R 3=1.0460 \mathrm{~m}^{2^{0}} \mathrm{C} / W
\end{aligned}
$$


and

$$
U=0.6535 \mathrm{~W} / \mathrm{m}^{2}{ }^{0} \mathrm{C}
$$

while finally,

$$
R_{T}=\frac{1}{U}=1.53 m^{20} \mathrm{C} / W
$$

where $R_{1}, R_{2}, R_{3}$ are the thermal resistances of each layer of the concrete block (fig. 17), $U$ the analytical value of the thermal transmittance of the block and $R_{T}$ the analytical thermal resistance of the block.

Consequently after the analytical calculations as well as the experimental several measurements the below results have been extracted concerning the thermal resistance of the block which easily can be compared with the manufacturer value. (table 6).

\section{Table 6: Thermal Resistance of the Concrete Block}

\begin{tabular}{|l|l|}
\hline Manufacturing thermal resistance & $1.58 \mathrm{~m}^{2^{0}} \mathrm{C} / \mathrm{W}$ \\
\hline Analytical thermal resistance & $1.53 \mathrm{~m}^{2^{0}} \mathrm{C} / \mathrm{W}$ \\
\hline Experimental thermal resistance & $1.67 \mathrm{~m}^{2^{0}} \mathrm{C} / \mathrm{W}$ \\
\hline
\end{tabular}

\subsection{Error Analysis}

The relative error among the analytical and the manufacturers R-values is $3.2 \%$ which was expected due to the experimental errors but also due to the errors of the partial R-values of each layer inside the concrete block. We have chosen as materials standard concrete and polystyrene for the analytical calculations needs. However it is reasonable that both of the values are close enough as well as that the Ranalytical value is lower than the manufacturer's one (which means higher thermal resistance).

As anticipated the experimental R-value is higher than the manufacturing value where the relative error reaches the 5.6\%. Although we have tested the hot-box more improvement can be made regarding the heat losses as well as the possible heat flow escape through the MDF board and the gypsum board at the top of the box. By the other hand gypsum as insulation material is effective enough but not the one with the higher performance. Changing or improving the insulation material of the box, we assume that the relative error will be further decreased. 
As it is presented to the following table 8, the random error for each measurement has been calculated providing by this way the uncertainty in each measurement we have done. The temperature symbols are referred to figure 11.

Table 8: Random Errors

\begin{tabular}{|c|c|c|}
\hline $\begin{array}{c}\text { Temperatures- Hot box Various } \\
\text { positions } \\
\text { (Fig. 11) }\end{array}$ & $\begin{array}{c}\text { Standard Deviation } \\
\left(\boldsymbol{\sigma}_{\boldsymbol{x}}\right)\end{array}$ & $\begin{array}{c}\text { Standard deviation of the } \\
\text { mean }\left(\boldsymbol{\sigma}_{\overline{\boldsymbol{x}}}\right)\end{array}$ \\
\hline T source & 0.408 & 0.167 \\
\hline Thair & 0.158 & 0.065 \\
\hline Thmid & 0.135 & 0.055 \\
\hline Tcmid & 0.129 & 0.053 \\
\hline Tcair & 0.131 & 0.053 \\
\hline
\end{tabular}

\section{Conclusions}

The experimental analysis, set, testing, evaluation and validation have been developed and achieved of the most popular insulation techniques which are applied in domestic buildings in Bahrain. In order to succeed it manufacturing data have been collected for various concrete blocks, concluding to the mist popular one in this region which is the 8 ', insulation block with polystyrene layers. An experimental unit (hot box) has been built, in order to measure the temperature distribution before, through and after the block simulating by this way its performance to a wall of a domestic building. The design of the box has been achieved giving high priority to the minimization of the heat losses through the hot - box walls and cover. This unit is appropriate for blocks testing only. The experimental thermal resistance value of the concrete block has been measured and estimated equal to $1.67 \mathrm{~m}^{2}{ }^{0} \mathrm{C} / W$ while the relative error with the manufacturer's value is close to $5.6 \%$. This error is probably due to the minor heat losses through the walls of the box, the potential thermal bridges between the sample and the walls of the apparatus and the partial experimental errors of each temperature measurement. Further improvement can be applied to the experimental set up or to the procedure which has been followed. Some of our priorities for further research are to improve even further the insulation of 
the hot box testing the possible heat losses and introduce a second thermostat in order to ensure in a short period of time the steady state. However our next aim is to make proposals for the optimization of the insulation techniques in Bahrain, testing even other types of blocks either specifying the optimum thermal insulation thickness and type according to the climate zone.

\section{Acknowledgments}

The authors would like to express their appreciation to Mr. Balagapal Menon from RedX, Mr. Taqi Marzooq from Bahrain Blocks as well as the companies Al Manaratain Sehla, Bahrain Blocks and Electricity and Water Authority for their useful information and valuable support to our research work.

\section{Funding statement}

Bahrain Polytechnic has fully supported the above research work as academic sponsor. However the authors received no particular financial support for the research, authorship, and/or publication of this article.

\section{References}

[1] Mohanadi A., (2006), Thermal Insulation in Buildings, Kingdom of Bahrain, Ministry of Electricity and Water.

[2] Zhou A., Wong K., Lau D., Thermal Insulating concrete wall panel design for sustainable built environment, The scientific world journal, vol. 2014, 2014.

[3] Mavromatidis L., El Mankibi M., Michel P., Santamouris M., Numerical estimation of time lags and decrement factors for wall complexes including multilayer thermal insulation in two different climate zones, Applied Energy, vol. 92, pp.480-491, 2012.

[4] Mavromatidis L., Michel P.,El Mankibi M., Santamouris M., Study on Transient heat trasfer through 
multi layer thermal insulation: numerical analysis and experimental investigation, Building Simulation, vol. 3, pp. 279-294, 2010.

[5] Mavromatidis L., El Mankibi M., Michel P., Bykalyuk A., Santamouris M., (2012), Guidelines to study numerically and experimentally reflective insulation systems as applied to buildings, Advances in Building Energy research, vol. 6, pp.2-35.

[6] Zupancic B., Sodja A., Object oriented modeling of variable envelope propertiesin buildings, WSEAS Transactions on Systems and control, vol. 3, pp. 1046-1056, 2008.

[7] Sodja A., Zopancic B., Modelling thermal processes in buildings using an object-oriented approach and modelica, Simulation Modelling practice and Theory, vol. 17, pp. 1143-1159, 2009.

[8] Calbureanu M., Lungu M., Tutunea D., Malciu R., Dima A., Modeling with finite element the convective heat transfer in civil buildings EPS insulated walls, Selected topics in Applied Computer Science, vol 1, pp. 79-84.

[9] Scotnicova I., Tymova P., Zdenek G., Lausova L., Numerical Analysis and experimental validation of the thermal response of light weight timber frame structures, Recent advances in Applied and Theoretical Mathematics, ISBN: 978-960-474-351-3

[10] Azemati A., Hosseini H., Investigation on the effect of building paint on energy shaving in different climates, Recent advances in Environmental Science, ISBN: 978-1-61804-167-8

[11] Moghimi S., Raatjes B., Moorsel P., Azizpour F., Mat S., Lim C., Sopian K., Optimum insulation material and thickness in the external walls and determination of the energy saving cost in hospital: case study in Malaysia, Advances in Environment, Biotechnology and biomedicine, ISBN: 978-1-61804-1227

[12] Taleb H., Simulation study on the heat trsnfer by improving the skin of hospital buildings in UAE, Recent advances in Fluid Mechanics and Thermal Engineering, ISBN: 978-1-61804-311-5

[13] Vrachopoulos M., Koukou M., Kotsiovelos E., Kravarritis E., Ioannidou P., Experimental evaluation of 
the performance of reflective insulation for improvement of indoor thermal environmental conditions, Proc. Of WSEAS Int. Conference on Energy \& Environmental Systems, Greece, may 2006.

[14] Rehman H., Steady state experimental analysis of various solar insulation materials and techniques for buildings in climate condition of Ras Al Khaimah, UAE, Energy Procedia, vol. 75, pp.1419-1424, 2015

[15] Grynning S., Jelle P., Uvlokk S., Gustavsen A., Baeterns R., Caps R., Meloysund V., "Hot box investigations and theoretical assessment of miscellaneous vacuum panel configurations in building envelopes”, Journal of Building Physics, vol. 34, pp. 297-324.

[16] Stazi F., Veglio A., Perna C., Munafo P., Experimental comparison between 3 different traditional wall constructions and dynamic simulations to identify optimal thermal insulation strategies, Energy and Buildings, vil.69, pp. 429-441, 2013.

[17] Becker R., "Air permeability and thermal performance of concrete block wall speciments", Journal of Building Physics, vol. 34, pp. 163-177.

[18] Saber H., "Practical correlation for thermal resistance of horizontal enclosed airspaces with downward heat flow for building applications", Journal of Building Physics, vol. 37, pp. 403-435.

[19] Saber H., Maref W., Sherrer G., Swinton C., "Numerical modeling and experimental investigations of thermal performance of reflective insulations", vol. 36, pp. 163-177.

[20] Sveipe E., Jelle P., Wegger E., Uvslokk S., Grynning S., Thue V., Time B., Gustavsen A., "Improving thermal insulation of timber frame walls by retrofitting with vacuum insulation panels-experimental and theoretical investigations", Journal of Building Physics, vol. 35, pp. 168-188.

[21] N. A. a. R. Flanagan, "The need of sustainable buildings construction in the Kingdom of Bahrain," Building and Environment, pp. 495-506, 2007.

[22] Hadrhami L., Ahmad A., Assessment of thermal performance of different types of mansory bricks used in Saudi Arabia, Applied Thermal Engineering, vol. 29, pp.1123-1130, 2009.

[23] Nuaimi S., Khamis A., Energy Saving in Buildings in Bahrain: Suitability of concrete blocks, J. of 
Advanced Science and Engineering Research, vol. 3, pp. 294-308, 2013.

[24] Svoboda Z., Kubr M., "Numerical simulation of heat transfer hollow bricks in the vertical direction", Journal of Building Physics, vol. 34, pp. 325-350.

[25] Pavlic Z., Jerman M., Trnik A., Koci V., Cerny R., "Effective thermal conductivity of hollow bricks with cavities filled by air and expanded polystyrene", Journal of Building Physics, vol. 37, pp.436-448.

[26] Meng X., Gao Y., Wang Y., Yan B., Zhang W., Long E., Feasibility experiment on the simple hot boxheat flow meter method and the optimization based on simulation reproduction, Applied Thermal Engineering, vol. 83, pp.48-56, 2015.

[27] W. S. Z. L. K. Z. Dingyi Yang, "Research on improving the heat insulation and presevation properties of small size concerete hollow blocks," Cement and Concrete Research , vol. 33, no. 9, pp. 1357-1361, 2003.

[28] http://solargis.info/doc/free-solar-radiation-maps-GHI

[29] Electricity \& Water Conservation Directorate Guide Lines for Thermal Insulation Implementation in Buildings, “Insulation Materials \& Systems," pp. 1-20.

[30] Country overview for Bahrain, Retrieved from Weather 2: http://www.myweather2.com/citytown/Bahrain/Bahrain/climate-profile.aspx?month=6, 2015

[31] Vivancos J., Soto J., Perez I., Ros-Lis J., Manez R., A new model based on experimental results for the thermal characterization of bricks, Buildings and Environment, vol. 44, 1047-1052, 2009.

[32] Asdrubali F., Baldinelli G., Thermal trnsittance measurements with the hot box method: calibration, experimental procedures and uncertainty analyses of three different approaches, Energy and Buildings, vol. 43, pp.1618-1626, 2011. 
[33] Haavi T., Jelle P, Guvstavsen A., Vacuum insulation panels in wood frame wall constructions with different stood profiles", Journal of Building Physics, vol. 36, pp. 212-226.

[34] Ghosh A., Ghosh S., Neogi S., (2014), "Performance evaluation of a guarded hot box U-value measurement facility under different software based temperature control strategies", Energy Procedia, vol. 54, pp. 448-454. 